\title{
Analysis of quality of life and associated factors in a group of elderly persons with supplemental health plans in the city of São Paulo, Brazil
}

Maria Elisa Gonzalez Manso $0^{1,2}$ (D) Leandro Tadeu Prazeres Maresti ${ }^{3}$ ID Henrique Souza Barros de Oliveira² ${ }^{\mathbb{D}}$

Abstract

Objective: To measure the Quality of Life (QoL) and associated factors in a group of elderly persons receiving care through a health plan operator in the city of São Paulo, Brazil. Method: A cross-sectional study was carried out with 169 elderly persons enrolled in a health plan and who were participants in a program to promote health and prevent risks and diseases. The Bref and Old versions of the World Health Organization Quality of Life (WHOQOL) instruments were adopted for the evaluation of the QoL of the elderly. After descriptive analysis, a comparative analysis was performed through the Student's t-tests and ANOVA. The Brown-Forsythe test was applied for situations in which no homogeneity was found and the Tukey test for multiple comparisons was applied. Results: The highest mean QoL values were found in the Psychological [72.1 ( \pm 14.3$)]$ and Environment $[68( \pm 15.4)]$ and Intimacy $[72.5( \pm 20.8)]$ domains, while the worst results were found in the Physical $[64.3( \pm 18)]$ domain and in the Death and Dying facet $[61.2( \pm 23.2)]$. In this group, factors such as obesity, neoplasia and previous hospitalizations were negatively associated with QoL, whereas young elderly, female, widows, carriers of chronic noncommunicable diseases and those limited to two morbidities, who practiced physical activity and had clinical care provided by a reference physician had a positive influence. Conclusion: The findings of this research showed high levels of satisfaction with health and QoL, in addition to raising relevant discussions about predictors that influence the QoL of the elderly receiving care from the supplementary sector. It also emphasizes the need for new strategies of action to ensure improvements in the health care of the elderly.

Keywords: Health of the Elderly. Quality of Life. Population Dynamics. Health Promotion. Prepaid Health Plans.

\footnotetext{
Pontifícia Universidade Católica de São Paulo (PUC-SP), Coordenadoria Geral de Especialização, Aperfeiçoamento e Extensão. São Paulo, SP, Brasil.

2 Centro Universitário São Camilo (CUSC-SP), Faculdade de Medicina. São Paulo, SP, Brasil.

3 Informar Saúde Teleorientações, Unidade de Pesquisa e Educação Continuada. São Paulo, SP, Brasil.
}

The authors declare that there are no conflicts of interest in relation to this study.

No funding was provided for this study. 


\section{INTRODUCTION}

According to the 2010 Brazilian Institute of Geography and Statistics (or IBGE) census, the elderly population and life expectancy have been growing significantly in Brazil ${ }^{1}$. However, increased life expectancy is not necessarily associated with improved quality of life (QoL). The latter is conceptualized by the World Health Organization (WHO) as "the individual's perception of their position in life in the context of the culture and value systems in which they live and in relation to their goals, expectations, standards and concerns". It is a polysemic definition, the components of which may vary from researcher to researcher ${ }^{2}$.

The evaluation of the QoL of the elderly covers several aspects, such as: functional capacity; socioeconomic level; psychological state; social interaction; intellectual activity; self-care; family support; sociocultural, ethical and religious values; the process of death and dying; lifestyle; satisfaction with job and/or activities of daily living; the environment in which one lives and which one frequents. It is known that the changes caused by the physiological and pathological process of aging tally with a reduction in the QoL of this group, justifying the relevance of studies that support strategies and actions aimed at prevention and the maintenance of active aging ${ }^{3}$.

Currently, the supplementary health sector in Brazil assists in the health needs of approximately $30 \%$ of the country's population, of which about $14 \%$ are elderly, and is characterized by offering prepaid health plans or health insurance. These services offer the same coverage as the public sector, but have their own networks of clinics, laboratories and hospitals throughout the country. It is also noted that the elderly population that receives care from the supplementary health sector has different demographic and socioeconomic conditions in relation to income, access, education and age than the majority of the elderly Brazilian population ${ }^{4}$.

There are few Brazilian studies focused on this sector, and for some years the country's government has been encouraging public policies aimed at this population segment and contributing to changes in the service provision model of health plan operators
(HPO), which still focus their health care on illness. Thus, since 2005, the Brazilian government has been discussing programs that meet the health specificities of the elderly they serve with companies that sell health plans. The intention is to transform this model into one centered on the person and the integrated health care of the individual, with progressive implementations of health promotion and risk and disease prevention actions $s^{5-7}$.

These actions, carried out in the form of programs, seek to stimulate self-care, emphasizing health education, with the main objective of preventing both the emergence of non-communicable chronic diseases (NCDs) and the triggering of such illnesses. However, there has been little progress in this field, mainly due to poor knowledge about the health of those receiving care from $\mathrm{HPO}^{5-7}$.

The aim of the present study was to measure the quality of life and the main factors associated with the same in a group of elderly persons participating in the chronic disease prevention program of a health insurance company, in the city of São Paulo, in the state of the same name, in Brazil.

\section{METHOD}

A quantitative, descriptive, exploratory and crosssectional study was conducted between December 2017 and August 2018 by applying the instruments to people aged 60 years of age and over, receiving care from a HPO and who participated in a program for the prevention of NCDs and their complications, in the city of Sao Paulo, Brazil.

The program to which this group of elderly participants in this study is linked is offered by the HPO and is carried out and coordinated by a multidisciplinary team, ensuring the continuous accompanying, evaluation and monitoring of participants through health indicators. The clinical management of the elderly receiving care is carried out through monthly telephone monitoring and home visits, during which the clinical status of the individuals is assessed ${ }^{6,7}$.

Entry and adherence to this program are spontaneous, and there is a requirement of having 
at least one NCD diagnosed by a doctor. There is no time limit set on remaining in the program.

The sample size of the present study was calculated within the total of the 301 elderly participants of the program. Applying the Central Limit Theorem, a sampling error of $5 \%$ and a confidence interval of 95\% were considered, resulting in a representative sample of 169 elderly persons, randomly drawn from the participants of the described program. The only exclusion criterion adopted was the medical diagnosis of neuropsychiatric diseases that could prevent the elderly persons from answering the questions of the instruments, which require self-completion.

The instruments used were: a structured questionnaire to collect sociodemographic variables and health status data and the World Health Organization Quality of Life-Bref (WHOQOLBref) and the World Health Organization Quality of Life Assessment for Older Adults (WHOQOLOld) instruments to measure the QoL of the elderly participants $^{8,9}$.

The structured questionnaire was designed by the researchers and addressed the sociodemographic characteristics of the researched elderly, such as: age; sex; marital and occupational status; and questions regarding health status such as: sedentary lifestyle, characterized by the absence of supervised physical activity; obesity measured by body mass index (BMI), according to the cutoff levels for age ${ }^{10}$; presence of degenerative chronic diseases under treatment at the time of the interview; date of last medical appointment; if the elderly had a specific referring physician and the presence or absence of hospitalizations in the previous year.

The QoL of the elderly was measured using the WHOQoL-Bref and WHQOL-Old instruments, both developed by The WHOQOL Group in 1998 and cross-culturally adapted for Brazil in 2000 8,11 . These instruments were tested in previous studies and presented satisfactory psychometric properties in the investigation of QoL in Brazilian elderly persons.

The WHOQOL-Bref, an abbreviated form of the WHOQOL-100, is composed of 26 questions, two general, related to QoL and overall health and 24 that make up the four domains: a) Physical; b) Environment; c) Psychological; and d) Social Relationships. It is used in conjunction with the WHOQOL-Old module, which consists of 24 questions assigned to six facets: a) Functioning of the Senses; b) Autonomy; c) Past Activities, d) Present and Future; e) Death and dying; and f) intimacy. The WHOQOL-Old is a specific instrument for the assessment of QoL in the elderly and should be applied in conjunction with the WHOQOL-Bref'.

Data was collected through home visits, previously scheduled by telephone, with the contact information of the participants provided by the HPO. During the contact, the purpose of the research was explained to the elderly, making it clear that their participation was voluntary and that their non-acceptance would not interfere with the care provided by the health plan. Following this stage, the information obtained through the visits was submitted to review and codification. The collected data were stored in electronic medical records and later transferred and stored in the study database. If inconsistent data were found between the databases, corrections were made by consulting the original interview.

The answers obtained through the self-applicable instruments were consolidated with their respective syntax, with the WHOQOL-Bref domains and WHOQOL-Old facets analyzed separately. The scores were calculated using a syntax developed and recommended by The WHOQOL Group, for the

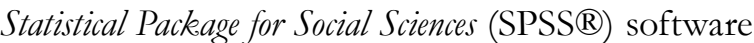
package. In general, each domain/facet was represented in percentage scores from zero to 100 , with the highest value corresponding to a better perception of $\mathrm{QOL}^{12}$.

Data analysis followed descriptive statistics. For the comparison between the domains/facets of the WHOQOL instruments and the variables of the two groups, presented above, the Student t test was applied. In the comparison between variables with three or more groups, analysis of variance (ANOVA) was performed. For situations where no homogeneity was found, adjustment was performed using the Brown-Forsythe Test. In multiple comparisons, the Tukey test was applied.

All results were analyzed by the SPSS software, and a criterion for determining statistical significance of $5 \%(p<0.05)$ was adopted. 
The research project was approved by the Ethics Research Committee of the Pontifícia Universidade Católica de São Paulo (PUC-SP), under opinion $\mathrm{n}^{\circ}$ 2.284.626, following the regulations of National Health Council Resolution n ${ }^{\circ} 466 / 2012$. The elderly were only contacted once this approval was obtained.

\section{RESULTS}

The sample of this study consisted of 169 elderly persons, most of whom were male ( $n=87 ; 51.5 \%)$, had a mean age of $71.6( \pm 8.0)$ years, were married and retired, as shown in Table 1. Regarding the clinical conditions and lifestyle of the elderly, the most prevalent NCD was systemic arterial hypertension, followed by type 2 diabetes mellitus. The elderly were largely sedentary, with a mean number of comorbidities of $2.4( \pm 1.2)$ NCDs, ranging from one to five diseases. It was also observed that most were assisted on a consistent basis by the same referral physician, with consultations in the previous six months. Several had a previous history of hospitalization, with more than two hospitalizations per year.

In QoL measurement, the WHOQOL-Bref domains with the highest scores were Psychological $[\mathrm{M}=72.1( \pm 14.3)]$ and Environment $[\mathrm{M}=68.0( \pm 15.4)]$, while the lowest score was Physical $[\mathrm{M}=64.3( \pm 18.0)]$, as shown in Table 2.

The evaluation of the two general and initial questions determined that $75 \%(n=127)$ of the elderly rated their QoL as good or very good and $63.6 \%(n=108)$ stated that they were satisfied with their health.

Regarding the WHOQOL-Old, as shown in Table 3, the facets with the best scores were: Intimacy $[\mathrm{M}=72.5( \pm 20.8)]$ and Sensory Functioning $[\mathrm{M}=70.3( \pm 20.3)]$, while the worst was Death and Dying $[M=61.2( \pm 23.2)]$. The total score of the WHOQOL-Bref was higher than that of the WHOQOL-Old.

Table 1. Sociodemographic and clinical characteristics of an elderly group $(\mathrm{N}=169)$ receiving care from a health plan operator. São Paulo, 2018.

\begin{tabular}{ll}
\hline Variables & $\mathrm{n}(\%)$ \\
\hline Sex & \\
Male & $87(51.5)$ \\
Female & $82(48.5)$ \\
\hline Age (years) & \\
$60-70$ & $82(48.5)$ \\
$\geq 71$ & $87(51.5)$ \\
\hline Marital Status & \\
Married & $109(64.5)$ \\
Widower & $36(21.3)$ \\
Not married & $21(12.4)$ \\
Others & $03(1.8)$ \\
Occupational status & \\
Retired & $128(75.7)$ \\
Active & $25(14.8)$ \\
Pensioner & $14(8.3)$ \\
Economic dependent & $02(1.2)$ \\
Chronic Non-Communicative Disease & \\
Arterial hypertension & $119(70.4)$ \\
Diabetes mellitus & $63(37.3)$ \\
Cancer & $42(24.9)$ \\
Depression & $13(7.7)$ \\
Chronic pain & $06(3.6)$ \\
Obesity & $42(24.9)$ \\
\hline
\end{tabular}


Continuation of Table 4

\begin{tabular}{ll}
\hline Variables & $\mathrm{n}(\%)$ \\
\hline Sedentarism & $91(53.8)$ \\
\hline Comorbidities & $90(53.2)$ \\
$0-2$ & $79(46.7)$ \\
$\geq 3$ & $159(94.1)$ \\
\hline Has referral physician & $149(88.2)$ \\
Last doctor's appointment & $20(11.8)$ \\
Less than six months & \\
Between six months and one year & $61(36.1)$ \\
Hospitalization & $108(63.9)$ \\
Never been hospitalized & $65(38.5)$ \\
Been hospitalized & $104(61.5)$ \\
Up to twice in the last year & \\
Interned more than twice in the last year &
\end{tabular}

Table 2. WHOQOL-Bref instrument scores in the group of elderly persons $(\mathrm{N}=169)$ receiving care from a health plan operator. São Paulo, 2018.

\begin{tabular}{llll}
\hline Domains & Mean (standard deviation) & Median & Minimum-Maximum \\
\hline Physical & $64.3( \pm 18.0)$ & 64.3 & $14.3-100$ \\
Psychological & $72.1( \pm 14.3)$ & 75.0 & $25.0-100$ \\
Social relationships & $67.4( \pm 18.8)$ & 66.7 & $16.7-100$ \\
Environment & $68.0( \pm 15.4)$ & 68.8 & $31.3-100$ \\
Q1 ${ }^{*}$ & $75.0( \pm 18.4)$ & 75.0 & $25.0-100$ \\
Q2 $* *$ & $63.6( \pm 24.3)$ & 75.0 & $0.0-100$ \\
Total score & $67.93( \pm 13.5)$ & 70.19 & $37.50-98.08$ \\
\hline
\end{tabular}

$* \mathrm{Q} 1=$ WHOQOL-Bref question $1-$ How would you rate your quality of life? $* * \mathrm{Q} 2=$ WHOQOL-Bref question $2-$ How satisfied are you with your bealth?

Table 3. WHOQOL-Old instrument scores in the group of elderly persons $(\mathrm{N}=169)$ receiving care from a health plan operator. São Paulo, 2018.

\begin{tabular}{llll}
\hline Facets & Mean (standard-deviation) & Median & Minimum-Maximum \\
\hline Sensory Functioning & $70.3( \pm 20.3)$ & 75.0 & $25.0-100$ \\
Autonomy & $65.1( \pm 17.7)$ & 68.8 & $12.5-100$ \\
Past, Present and Future Activities & $66.4(15.6)$ & 68.8 & $25.0-100$ \\
Social Participation & $63.8(17.2)$ & 68.8 & $18.8-100$ \\
Death and dying & $61.2(23.2)$ & 62.5 & $0.0-100$ \\
Intimacy & $72.5(20.8)$ & 75.0 & $0.0-100$ \\
Total score & $66.5( \pm 11.1)$ & 66.7 & $34.4-88.5$ \\
\hline
\end{tabular}


It was observed that the lowest scores were among (a) elderly persons with neoplasia in the Social Relations domain ( $p=0.042$ ); (b) obese elderly persons in the Social Participation facet $(p=0.025)$ and (c) elderly persons with previous hospitalizations in the Physical ( $p=0.001)$, Psychological $(p=0.042)$, Social Relations $(p=0.07)$ domains, total score $(p=0.007)$ and the Autonomy ( $\phi=0.020)$, Past, Present and Future Activities ( $p=0.001)$, Social Participation $(p<0.001)$ and Intimacy $(p<0.001)$ facets, and the WHOQOL-Old total score $(p<0.001)$.

In contrast, some factors were found with the highest scores in certain domains/facets such as: (a) female gender and the Environment domain $(p=0.009)$, and the Sensory Functioning $(p<0.001)$ and Intimacy ( $p=0.027$ ) facets; (b) age range up to 70 years and the Physical domain $(p=0.001)$; (c) widowers and the Autonomy facet ( $p=0.040$ ); (d) nonretired elderly persons and the Sensory Function facet $(p=0.010)$; (e) elderly persons with less than two comorbidities and the Physical domain ( $p=0.046)$; (f) those with hypertension and WHOQOL-Old total score $(p=0.045)$; (g) not having depression and the Psychological $(p<0.001)$, Social Relations $(p<0.001)$, Environment $(p=0.005)$ domains, WHOQOL-Bref total score $(p<0.001)$, the Past, Present and Future Activities $(p<0.001)$, Social Participation ( $p=0.002)$, and Intimacy $(p=0.004)$ facets and WHOQOL-Old total score $(p=0.020)$; (h) practice of physical activity practice and the Physical domain ( $p=0.004)$, the Past, Present and Future Activities facet $(p=0.007)$ and WHOQOL-Old total score ( $p=0.026)$; (i) being treated by a referral physician and the Physical domain $(p=0.002)$.

\section{DISCUSSION}

The elderly group surveyed was characterized by a slight predominance of male elderly persons, which differs from most groups presented in literature, where there are a majority of women in this type of program, especially in the southeast region of Brazil. Regarding the sociodemographic characteristics of the elderly linked to the Brazilian supplementary health sector, the largest coverage is concentrated in those who are married, retired and aged over 70 years, especially 80 and over, data which corroborated those found in this research ${ }^{6,7,13,14}$.
Noncommunicable diseases and injuries (NCDs) - which encompass NCDs and violence and accidents - currently represent the major cause of demand for health services, morbidity and mortality, disability and a decrease in the QoL of the world's elderly population, accounting for $81.2 \%$ of deaths in the city of São Paulo, a proportion that has been growing every year ${ }^{15-17}$.

NCDs or chronic degenerative diseases represent a group of diseases with a multiplicity of risk factors, the etiology of which is not fully elucidated, which develop for many years, are asymptomatic, capable of generating irreversible injuries and complications that determine varying degrees of disability and even death. Among the NCDs, which are responsible for up to $75 \%$ of São Paulo deaths, conditions such as cardiocirculatory, neoplastic and metabolic diseases stand out ${ }^{14}$. In the present study, a predominance of hypertension was observed, followed by diabetes mellitus, neoplasms and obesity, similar to the distribution shown in the literature, in studies with similar groups $s^{7,16,17}$.

It is also known that the longer the elderly live, the greater are the number of chronic conditions and their prevalence, giving rise to the presence of comorbidities - the concomitant occurrence of two or more diseases in the same individual - a factor directly related to greater functional disability ${ }^{18,19}$. In the researched group, the prevalence of multiple comorbidities is notable, which, combined with the high average age, may demonstrate a higher risk of loss of autonomy and independence for these people, as highlighted in the literature $\mathrm{e}^{7,14,18}$.

It is noteworthy that these elderly persons, who are treated by a referral physician, with a predominance of consultations less than six months prior to the study, corroborate the importance of educational programs to improve adherence to treatment. Even so, more than half of the group had been hospitalized at least once in their lifetime, and nearly $62 \%$ of the elderly surveyed had been hospitalized more than twice in the last year, even though they have had regularly health appointments, a fact of concern to researchers, and which is notable in relation to the literature.

Regarding QoL, the WHOQOL-Bref domains in which the elderly people had the highest score and, 
consequently, the highest level of satisfaction, were the Psychological, followed by the Environment, which differs from other studies with Brazilian elderly persons, which found higher average scores in the Social Relationships domain ${ }^{19-23}$.

The performance of this group in the Psychological domain shows how satisfied they are regarding issues related to feelings, self-esteem, appearance, memory, concentration, spirituality and personal beliefs, in contrast to other previously studied groups that suffer from the process of adapting to senescence ${ }^{21}$.

The Environment domain evaluates the environment in which the elderly are inserted, encompassing aspects related to housing conditions; socialization; transport; physical safety; recreation; financial resources and protection. It is noteworthy that in most Brazilian studies found and conducted with the elderly, this domain usually has lower scores, impairing the assessment of QoL, a finding contrary to that which was observed in the present study ${ }^{20,23,24}$. The fact that the elderly surveyed live in a large city and have different income and access characteristics, as already mentioned, may explain the strong performance of this group in the Environment domain.

In contrast, the worst performance was noted in the Physical domain, which also diverges from literature. It is believed that the fact that there are elderly people in the group who, in addition to already having a NCD, have comorbidities and high levels of previous hospitalizations, may explain this finding, since these are conditions that may limit their performance of activities of daily living with an impact on $\mathrm{QoL}^{18,22}$.

Regarding the two general questions of WHOQOL-Bref, it was found that most of the elderly were satisfied or very satisfied with their health, also presenting a good perception of overall QoL. This result shows that most of the elderly in this group have a positive perception of their QoL and their health condition, up to the time of the interview.

The analysis of the facets of the WHOQOL-Old instrument found a higher mean score in the Intimacy facet and a lower mean score for Death and Dying. It is noteworthy that, although the results found in this study are compatible with those found in other studies conducted with elderly patients with NCDs, the average scores obtained by the elderly in this group are higher than those described in the literature ${ }^{21,23}$. The strong performance in the Intimacy facet can be explained by satisfaction with their coexistence and intimate relationships with their partners and those around them, given the predominance of married elderly persons living with their families. On the other hand, it is noted that there is a difficulty in accepting the process of death and dying in this group.

When analyzing which sociodemographic and clinical aspects are significantly associated with the QoL of the elderly in this study, some differences were observed in relation to other Brazilian studies aimed at measuring this construct in the elderly ${ }^{2,3,18-20,24}$.

Regarding gender, women in the surveyed group performed better than men in the Environment domain, the Sensory Functioning and the Intimacy facets, while widowed elderly performed better in the Autonomy facet. Both findings differ from the literature. Most studies find that women are more dissatisfied with their QoL in these domains, mainly related to the influences of psychosocial factors derived from the traditional role of women, highly present in the cohort of people today considered elderly ${ }^{18,24}$. It is noteworthy that the women in the researched group have their own characteristics that differentiate them from the majority of the Brazilian female elderly population: 52 (63\%) had a high educational level, with complete high school or higher educations, which is not characteristically observed in Brazilian elderly women. This condition may have influenced these results ${ }^{1}$.

Elderly persons who live without a partner and who have suffered significant losses during life tend to have less contact with family and friends, a low frequency of help received and provided, and resilience is not always observed in the process of loss and control of their autonomy, as found in this study group ${ }^{18,24}$.

The data for the relationship between young elderly persons, under 70 years old, and the Physical domain was not reported by other studies ${ }^{3,20}$. This finding can be attributed to the lower number of comorbidities 
and the degree of preservation of autonomy among these elderly persons, when compared to the older elderly persons in the group. The same applies to the relationship between non-retired elderly persons and the Sensory Functioning facet.

It can be inferred that for this group of elderly persons, widowhood, age and work seem to be protective factors that positively influence QoL, along with having less than two comorbidities, not having depression and being treated by a referral physician. The presence of chronic conditions, especially NCDs significantly affect the QoL of the elderly, but when these are diagnosed early, properly treated and preventive measures are instituted, with the encouragement of self-care and the prevention of systemic complications resulting from these diseases, the independence and autonomy of the elderly are preserved $^{18-20,24}$.

It is also noteworthy that higher levels of continuity of care, in any setting, with any group of people, involving both primary care physicians and specialists, are associated with lower rates of mortality. Continuity of care is associated with people with a physician who is more aware of such issues, the individualization of care received by the individual and the understanding of their needs, which may explain the finding in the present study ${ }^{25}$.

In this study, there was also a positive influence between the regular practice of physical activities and QoL. As reported in other studies, it is known that physical activity is a measure that can delay functional losses and prevent possible negative and unwanted outcomes ${ }^{2,20}$.

In this study, the presence of cancer and obesity were two characteristics negatively associated with both facets and domains related to social participation, bonds and affections, highlighting the difficulty of this group in participating in social activities and the need for affective support for these people.

The presence of a previous history of hospitalization was another association that affected, greatly and negatively, the QoL of these elderly people. During hospitalization, the elderly may evolve through a loss of functionality, also conceptualized as a hospital acquired infection (HAI), due to numerous factors: progression of the clinical condition; underlying previous diseases; the procedures to which they are submitted; difficulty in adapting to aging and frailty ${ }^{26}$. But in the hospital environment, loneliness, fear of death and other psychosocial issues also influence the elderly not only during the act, but even after discharge, as shown by the responses of this group.

The presence of a previous history of hospitalization was found. The results obtained in this study show significant factors in the assessment of QoL of a group of elderly persons receiving care from the Brazilian supplementary health sector, in the city of São Paulo, regarding sociodemographic, clinical and lifestyle aspects. However, these results should be interpreted with caution due to the particularities of the study group. In addition, the cross-sectional design of the study does not allow causal relationships to be established. Another limitation relates to the characteristics of the WHOQOL instruments used, as they are self-reporting instruments, and therefore subject to response bias.

\section{CONCLUSION}

The researched group had the best quality of life in the Psychological and Environment domains and in the Intimacy and Sensory Functioning facets. The group reported a high level of satisfaction with their health and overall quality of life. On the other hand, the elderly had a worse perception in the Physical domain and in the Death and Dying facet.

It was also noted that the female gender, widowhood, age, work, having less than two comorbidities, not having depression, being treated by a referral physician and practicing physical activity seem to be protective factors that positively influence the quality of life of this group. However, previous hospitalizations and the presence of obesity and cancer generate stress factors, negatively influencing the quality of life of this group of people.

It must be emphasized that the results of this study should be used and interpreted with caution, as they portray a differentiated group in terms of income, 
education, access to health services and treatment and who live in a more accessible environment.

The results of the present study raise important discussions about predictors that influence the quality of life of the elderly receiving care through the supplementary health sector and indicate the need for policies and action strategies that ensure improvements in care for the elderly in all their specificities and diversity.

Edited by: Ana Carolina Lima Cavaletti

\section{REFERENCES}

1. Instituto Brasileira de Geografia e Estatística. Síntese de Indicadores Sociais (SIS): uma análise das condições de vida da população brasileira 2015. Rio de Janeiro: IBGE; 2015.

2. Vagetti GC, Moreira NB, Barbosa Filho VC, Oliveira V, Cancian, CF, Mazzardo O, et al. Domínios da qualidade de vida associados à percepção de saúde: um estudo com idosas de um programa de atividade física em bairros de baixa renda de Curitiba, Paraná, Brasil. Ciênc Saúde Colet. 2013;18(12):3483-93.

3. Dawalibi NW, Goulart RMM, Prearo LC. Fatores relacionados à qualidade de vida de idosos em programas para a terceira idade. Ciênc Saúde Colet. 2014;19(8):3505-12.

4. Manso MEG, Maresti LTP, Osti AV. Program for prevention of falls among elders: experiences in a Brazilian health plan. MOJ Gerontol Geriatr. 2018;3(2):217-8.

5. Manso MEG. Envelhecimento, saúde do idoso e o setor de planos de saúde no Brasil. Rev Kairós. 2017;20(4):135-51.

6. Manso MEG, Câmara R, Souza SA, Maciel TD, Farina DBL. Programa de gerenciamento de doenças crônicas em um plano de saúde, São Paulo, Brasil. Ciênc Cuid Saúde. 2016;15(2):321-7.

7. Manso MEG, Osti AV, Maresti LTP, Borrozino NF. Análise do gerenciamento de doenças crônicas em uma operadora de planos de saúde na cidade de São Paulo. Rev SODEBRAS. 2018;13(151):77-82.

8. World Health Organization. WHOQOL: Measuring quality of life [Internet]. Genebra: WHO; 1997 [acesso em 30 dez. 2018]. Disponível em: https://www.who. int/mental_health/media/68.pdf

9. Fleck MPA, Chachamovich E, Trentini CM. Development and validation of the portuguese version of the WHOQOL-Old module. Rev Saúde Pública. 2006;40(5):785-91.

10. Pascali C, Peliello LC. Avaliação Nutricional. In: Manso MEG, organizador. Geriatria: Manual da Liga de Estudos do Processo de Envelhecimento. São Paulo: Martinari; 2015. p 91-104.

11. Fleck MPA, Louzada S, Xavier M, Chachamovich E, Vieira G, Santos L, et al. Aplicação da versão em português do instrumento abreviado de avaliação da qualidade de vida "WHOQOL-Bref”. Rev Saúde Pública. 2000;34(2):178-83.

12. Santos PM. Principais instrumentos de avaliação da qualidade de vida de idosos no Brasil: vantagens e desvantagens na utilização. Corpoconsciência. 2015;19(2):25-36.

13. Leite F. Envelhecimento populacional e a composição etária de beneficiários de planos de saúde. São Paulo: IESS; 2011.

14. Oliveira HSB, Sousa JRP, Donis ACG, Manso MEG. Utilização dos critérios de Beers para avaliação das prescrições em idosos portadores de doenças crônicas vinculadas a um plano de saúde. Rev Bras Ciênc Envelhec Hum. 2017;14(3):242-51.

15. Malta DC, Stopa SR, Szwarcwald CL, Gomes NL, Silva Júnior JB, Reis AAC. A vigilância e o monitoramento das principais doenças crônicas não transmissíveis no Brasil - Pesquisa Nacional de Saúde, 2013. Rev Bras Epidemiol. 2015;18(2):3-16.

16. Diniz MA, Tavares DMS. Fatores de risco para doenças cardiovasculares em idosos de um município do interior de Minas Gerais. Texto \& Contexto Enferm. 2013;22(4):885-92.

17. Manso MEG, Sousa JRP, Oliveira HSB. Analise do perfil neurogeriátrico de um grupo de idosos pertencentes a um plano de saúde do município de São Paulo, Brasil. Rev Kairósl. 2018;21(2):215-26.

18. Maciel NM, Conti MHS, Simeão SFAP, Corrente JE, Ruiz T, Vitta A. Morbidades referidas e qualidade de vida: estudo de base populacional. Fisioter Pesqui. 2016;23(1):91-7.

19. Amaral TLM, Amaral CA, Lima NS, Herculano PV, Prado PR, Monteiro GTR. Multimorbidade, depressão e qualidade de vida em idosos atendidos pela estratégia de saúde da família em Senador Guiomard, Acre, Brasil. Ciênc Saúde Colet. 2018;23(9):3077-84. 
20. Miranda LCV, Soares SM, Silva PAB. Qualidade de vida e fatores associados em idosos de um centro de referência à pessoa idosa. Ciênc Saúde Colet. 2016;21(11):3533-44.

21. Pereira RMP, Batista MA, Meira AS, Oliveira MP, Kusumota L. Qualidade de vida de idosos com doença renal crônica em tratamento conservador. Rev Bras Enferm. 2017;70(4):887-95.

22. Pilger C, Santos ROPS, Lentsck MH, Marques S, Kusumota L. Bem estar espiritual e qualidade de vida de idosos em tratamento hemodialítico. Rev Bras Enferm. 2017;70(4):721-9.

23. Lima LR, Funghetto SS, Valpe CRG, Santos WS, Funez MI, Stival MM. Qualidade de vida e o tempo do diagnóstico do diabetes mellitus em idosos. Rev Bras Geriatr Gerontol. 2018;21(2):180-90.
24. Ameida-Brasil CC, Silveira MR, Silva KR, Lima MG, Faria CDCM, Cardoso CL, et al. Qualidade de vida e características associadas: aplicação do WHOQOLBREF no contexto da atenção primária à saúde. Ciênc Saúde Colet. 2017;22(5):1705-16.

25. National Health Service [Internet]. Seeing same doctor every time "reduces risk of death". U.K: NHS; 2018 [acesso em 20 ago. 2018]. Disponível em: https://www.nhs.uk/news/medical-practice/seeingsame-doctor-every-time-reduces-risk-death/.

26. Carvalho TC, Valle AP, Jacinto AF, Mayoral VFS, Boas PJFV. Impacto da hospitalização na funcionalidade de idosos: estudo de corte. Rev Bras Geriatr Gerontol. 2018;21(2):134-42. 